\title{
An overview of randomized controlled trials on endovascular treatment for chronic cerebrospinal venous insufficiency in multiple sclerosis patients
}

\author{
Eine Übersicht randomisierter Studien zur endovaskulären \\ Behandlung der chronischen zerebrospinalen Veneninsuffizienz \\ bei Patienten mit multipler Sklerose
}

Author

Marian Simka

Affiliation

Department of Anatomy, University of Opole, Opole, Poland

Key words

chronic cerebrospinal venous insufficiency, internal jugular vein, multiple sclerosis, randomized clinical trial

\section{Schlüsselwörter}

chronische zerebrospinale Veneninsuffizienz, V. jugularis interna, multiple Sklerose, venöse Angioplastie

published online 09.04 .2020

Bibliography

Phlebologie 2021; 50: 76-80

DOI 10.1055/a-1061-3205

ISSN 0939-978X

(C) 2020. Thieme. All rights reserved.

Georg Thieme Verlag KG, Rüdigerstraße 14,

70469 Stuttgart, Germany

\section{Correspondence}

Marian Simka

Department of Anatomy, University of Opole, ul. Oleska 48, 45-052 Opole, Poland

mariansimka@poczta.onet.pl

\section{ABSTRACT}

About ten years ago it was hoped that venous angioplasty for abnormal veins, primarily the internal jugular veins, will be a much awaited treatment for multiple sclerosis. Yet, a majority of randomized clinical trials on endovascular treatment for chronic cerebrospinal venous insufficiency did not reveal clinical efficacy of these procedures in multiple sclerosis patients. Still, a detailed analysis of these trials suggests that they were poorly designed, underpowered and endovascular techniques used were often far from being optimal. Nonetheless, even considering weak points of these trials, it can be concluded that venous angioplasty should not be used as a routine treatment modality in multiple sclerosis patients. Still, a possibility that some patients may benefit from endovascular treatment cannot be ruled out. This may concern patients at early stage of the disease and presenting with lesions that can easily be managed with balloon angioplasty. Therefore, we need more studies evaluating clinical efficacy of venous angioplasty in selected subgroups of multiple sclerosis patients. Importantly, it has already been demonstrated that venous angioplasty in multiple sclerosis patients is a safe procedure. Thus, also from an ethical point of view, such trials seem justifiable.

\section{ZUSAMMENFASSUNG}

Vor 10 Jahren wurden Studien vorgestellt, die die venöse Angioplastie bei Gefäßläsionen der V. jugularis interna als lang erwartete Behandlungsmöglichkeit der multiplen Sklerose vorstellten. Allerdings ergaben die daraufhin durchgeführten randomisierten klinischen Studien zur endovaskulären Behandlung bei chronischer zerebrospinaler Veneninsuffizienz sehr unterschiedliche Ergebnisse und im Wesentlichen keine Bestätigung der klinischen Wirksamkeit dieser Verfahren bei Patienten mit multipler Sklerose. Eine detaillierte Analyse dieser Studien lässt jedoch vermuten, dass die Studien schlecht konzipiert waren und möglicherweise nicht ausreichend Erfahrung mit den eingesetzten endovaskulären Techniken vorlag. Aber auch unter Berücksichtigung der Schwachstellen dieser Studien kann der Schluss gezogen werden, dass die venöse Angioplastie nicht als Routinebehandlung bei Multiple-Sklerose-Patienten eingesetzt werden sollte.

Allerdings scheint es so, dass die endovaskuläre Behandlung, wie im ursprünglichen Artikel dargestellt, bei einigen Patienten hilfreich sein kann. Das sind besonders Patienten in einem frühen Stadium der Krankheit, die Läsionen aufweisen, die mit einer Ballonangioplastie leicht zu behandeln sind. Daher sind weitere Studien notwendig, die die klinische Wirksamkeit der venösen Angioplastie in ausgewählten Untergruppen von Patienten mit multipler Sklerose untersuchen. Diese Studien erscheinen aus ethischer Sicht gerechtfertigt, da bereits erwiesen wurde, dass die venöse Angioplastie bei Patienten mit multipler Sklerose ein sicheres Verfahren ist. 


\section{Introduction}

Multiple sclerosis (MS) is a disease characterized by multifocal areas of inflammation and demyelination within the central nervous system. Of as yet, its etiology remains elusive. For the time being the ruling MS paradigm is the autoimmune one, which means that that it is caused by an autoimmune attack against nervous tissue, primarily executed by the myelin-reactive $\mathrm{CD}^{+}$and $\mathrm{CD}^{+} \mathrm{T}$ cells. Therapeutic strategies, which are more or less efficient, predominantly target this inflammatory process. Although MS is commonly regarded as an autoimmune disorder, some phenomena associated with MS, especially regarding its neurodegenerative aspects, do not fit into this autoimmune dogma. About 15 years ago, Italian surgeon Paolo Zamboni has suggested that MS may actually have a vascular background [1]. His research on this topic began from the observation of an anomalous flow in the cerebral sinuses and intracranial veins in MS patients. Then, his team revealed that many MS patients present with flow disturbances in the extracranial veins. Zamboni has coined the term chronic cerebrospinal venous insufficiency (CCSVI) to depict this clinical entity [2-5]. He suggested that venous abnormalities may play a primary role in initiating autoimmune reactions in MS patients and proposed that an accumulation of iron in the brain parenchyma may be responsible for the promotion of this disease [1]. In addition, a pilot study performed by his group demonstrated clinical improvement of MS symptoms after balloon angioplasty of pathological veins [6]. Therefore, it was hoped that venous angioplasty for abnormal extracranial veins will be a much awaited and efficient treatment for MS. Yet, although open-label studies demonstrated clinical improvements [7-12], a majority of randomized clinical trials with sham arms did not reveal efficacy of endovascular repair of such pathological veins. However, a detailed analysis of these trials suggests that they were poorly designed, underpowered and endovascular techniques used were often far from being optimal [13]. In this paper an overview of the results and designs of already completed and published randomized clinical trials on endovascular treatment for CCSVI in MS patients is presented. Since data provided by these publications were heterogeneous and incomplete, it was not possible to evaluate them statistically. Instead, a descriptive analysis was performed. It is hoped that such a critical analysis will be helpful in proper interpretation of the results of these trials.

\section{Research methods}

In order to identify all published randomized controlled trials on endovascular treatment for CCSVI in MS patients, a search of the ClinicalTrials.gov registry was performed. The terms "multiple sclerosis" and "angioplasty" were used, and then it was checked if the trials met the criteria of a prospective randomized trial and if such a trial was completed. In this way 3 trials were found. In addition, a literature search using the Google Scholar and PubMed data search engines, and the same keywords was performed. With this method the fourth trial has been identified. There were also found several other trials, but they were either of an openlabel design, or they were suspended/terminated. In addition, personal communications revealed some studies that are still ongoing and not yet published. All these studies were not considered in this analysis.

\section{Results}

Thus far, only 4 randomized controlled studies evaluating clinical efficacy of endovascular treatments for CCSVI in MS patients have been published [14-17]. All these studies were rather small and seem underpowered. The Brave Dreams trial, which was a multicenter Italian study, recruited the highest number of patients (76 vs. 39 patients in both arms of the trial). Other studies were even smaller. Three studies were designed as a sham-controlled trial, while one study was a randomized wait-list trial (no sham arm). Clinical characteristics of MS patients recruited to these trials is presented in $>$ Table $\mathbf{1}$. Patients from the Brave Dreams study differ from the patients recruited to the other studies they were younger, with a shorter duration of the disease and all of them presented with relapsing-remitting clinical course of MS (which is an early and less debilitating stage of the disease) [16]. On the contrary, patients recruited to other trials (the Pisa study did not provide all demographic data) were older, with longer duration of MS and heterogeneous clinical course of the disease.

Details of study designs and clinical outcomes of all four published studies are summarized in $\mathbf{T}$ Table 2 . Only the Pisa study reported clinical improvement after the treatment [14]. These improvements, however, regarded clinical-functional measures (comprising such clinical parameters as: severity of urinary urgency, timed-up-to-go test / the test assessing patient's mobility/, fatigue severity scale, numerical-rating scale for pain, multiple sclerosis quality-of-life assessment and hospital anxiety-depression scale), but not other assessed clinical parameters, such as evoked potentials composite functional outcomes and upper limb kinematic measures. However, since it was not a trial with the sham arm, this study should be interpreted with caution and, in terms of quality of study design, as inferior to the remaining trials. The Brave Dreams did not report better clinical outcomes, yet in the subgroup of patients with restored venous outflow after endovascular intervention, there were significantly fewer new MS lesions revealed by MRI [18]. Importantly, the number of new MS plaques demonstrated by MRI is widely accepted as the endpoint in clinical trials evaluating pharmacological treatment of MS. It is also uncertain if the angioplasties were performed properly from technical point of view. $>$ Table 3 includes information if these procedures were performed by interventionalists experienced in this particular treatment. Such interventionalists were regarded experienced, if they have published (or presented at scientific meetings) results of similar interventions, and the number of such interventions performed before the trial was reasonable. Of note, an experience in performing standard endovascular procedures is usually evaluated according to the guidelines [19]. Yet, endovascular treatments for CCSVI, of as yet, are not routine procedures and therefore a standard endovascular training should not be regarded as sufficient. Regarding one study (the PREMiSe study), it has been described that the interventionalists performed endovascular treatments for CCSVI in a few patients 
- Table 1 Clinical characteristics of MS patient participating in the trials.

\begin{tabular}{|l|l|l|l|l|}
\hline clinical study & $\begin{array}{l}\text { mean patients' } \\
\text { age [years] }\end{array}$ & $\begin{array}{l}\text { mean duration of } \\
\text { disease [years] }\end{array}$ & $\begin{array}{c}\text { clinical type of MS } \\
\text { [EDSS score] }\end{array}$ & all clinical types of MS \\
\hline PREMiSe study (USA) & 44.1 & 11.2 & all clinical types of MS \\
\hline Multicenter Canadian study (Canada) & $50.5 \mathrm{~s}$ & 17 & relapsing remitting MS \\
\hline Brave Dreams study (Italy) & 39.2 & 5.4 & 2-5.5 (2.6) \\
\hline $\begin{array}{l}\text { expanded analysis of the Brave } \\
\text { Dreams study (Italy) }\end{array}$ & 39.9 & 5.0 & secondary progressive MS \\
\hline \begin{tabular}{l} 
University of Pisa study (Italy) \\
\hline
\end{tabular} & 47.2 & data not provided & all clinical types of MS \\
\hline
\end{tabular}

- Table 2 Study designs and clinical outcomes of the trials.

\begin{tabular}{|c|c|c|c|c|c|}
\hline clinical study & $\begin{array}{l}\text { no of patients } \\
\text { (treatment/sham } \\
\text { or control group }\end{array}$ & study design & result of the study & $\begin{array}{l}\text { duration of } \\
\text { follow-up } \\
\text { [months] }\end{array}$ & remarks \\
\hline PREMiSe study (USA) & $9 / 10$ & $\begin{array}{l}\text { randomized single-center } \\
\text { sham-controlled double- } \\
\text { blind study }\end{array}$ & $\begin{array}{l}\text { not statistically significant } \\
\text { differences between } \\
\text { study arms }\end{array}$ & 6 & \\
\hline $\begin{array}{l}\text { Multicenter Canadian } \\
\text { study (Canada) }\end{array}$ & 49/55 & $\begin{array}{l}\text { randomized multicenter } \\
\text { sham-controlled double- } \\
\text { blind study }\end{array}$ & $\begin{array}{l}\text { not statistically significant } \\
\text { differences between } \\
\text { study arms }\end{array}$ & 11 & \\
\hline $\begin{array}{l}\text { Brave Dreams study } \\
\text { (Italy) }\end{array}$ & $76 / 39$ & $\begin{array}{l}\text { randomized multicenter } \\
\text { sham-controlled double- } \\
\text { blind study }\end{array}$ & $\begin{array}{l}\text { not statistically significant } \\
\text { differences between } \\
\text { study arms* }\end{array}$ & 12 & $\begin{array}{l}\text { * regarding clinical } \\
\text { symptoms of MS }\end{array}$ \\
\hline $\begin{array}{l}\text { expanded analysis of } \\
\text { the Brave Dreams } \\
\text { study (Italy) }\end{array}$ & $83 / 42$ & $\begin{array}{l}\text { randomized multicenter } \\
\text { sham-controlled double- } \\
\text { blind study }\end{array}$ & $\begin{array}{l}\text { statistically significant } \\
\text { lower probability of new } \\
\text { MS lesions in the treat- } \\
\text { ment arm** }\end{array}$ & 12 & $\begin{array}{l}{ }^{* *} \text { patients with favorable } \\
\text { morphology of CCSVI } \\
\text { lesions were significantly } \\
\text { more likely to be free } \\
\text { from new MS lesions }\end{array}$ \\
\hline $\begin{array}{l}\text { University of Pisa } \\
\text { study (Italy) }\end{array}$ & $31 / 35$ & $\begin{array}{l}\text { randomized single-center } \\
\text { wait list (not-sham) } \\
\text { controlled study }\end{array}$ & $\begin{array}{l}\text { statistically significant } \\
\text { improvement in the } \\
\text { treatment arm*** }\end{array}$ & 6 & $\begin{array}{l}* * * \text { only regarding } \\
\text { selected clinical } \\
\text { measures }\end{array}$ \\
\hline
\end{tabular}

before the proper study [14], which - considering technical difficulties associated with these procedures describes by more experienced authors [20] - should not be interpreted as adequate training. In both Italian studies angioplasties were performed by experienced interventionalists, while in the Canadian study these angioplasties were done by doctors who have never published or presented their results (except for this particular trial), and therefore should be regarded inexperienced. In addition, in > Table 3, there is provided information whether venous outflow after angioplasty has improved. Unfortunately, such information was given by two papers only (the PREMiSe and the Brave Dreams studies). Regarding remaining studies it is unclear if a post-procedural evaluation of the venous outflow in target veins was performed.

- Table 4 summarizes venographic definition of CCSVI that was interpreted as an indication for endovascular intervention. In all four trials MS patients were pre-screened by means of color Doppler sonography, and sonographic criteria of CCSVI [3] were used. Only those patients presenting with sonographic abnormal- ities in the internal jugular veins and/or vertebral veins we included. Yet, final decision upon endovascular angioplasty depended on the result of catheter venography. Interestingly, negative trials (the PREMiSe and the multicenter Canadian studies) applied the definition of $>50 \%$ luminal diameter reduction $[14,15,21]$. Other trials, which reported rather favorable clinical outcomes (at least in selected subgroups), applied more complex evaluation described in the ISNVD Consensus Documents [22, 23]. The criterion of $>50 \%$ luminal diameter reduction is widely used during endovascular interventions in the arteries. Yet, because of uniqueness of the venous outflow (flow under low pressure gradient, characterized by easy flow separation and associated high flow resistance), this criterion is of limited value in the veins. In this vascular territory other criteria, such as the presence of collateral network, decreased flow velocity or narrowing of the lumen visible on IVUS are routinely applied [22]. Of note, interventionalists from the PREMiSe study did not achieve hemodynamic improvement after interventions, and such an improvement was 
- Table 3 Experience of interventionalists and hemodynamic efficacy of venous angioplasty.

\begin{tabular}{|l|l|l|}
\hline clinical study & $\begin{array}{l}\text { procedures performed by interventionalists } \\
\text { experienced in endovascular treatment for CCSVI }\end{array}$ & $\begin{array}{l}\text { was angioplasty hemo-dynamically } \\
\text { effective }\end{array}$ \\
\hline PREMiSe study (USA) & no & no \\
\hline Multicenter Canadian study (Canada) & no & not reported \\
\hline Brave Dreams study (Italy) & yes & in $54 \%$ of patients \\
\hline University of Pisa study (Italy) & yes & not reported \\
\hline
\end{tabular}

- Table 4 Definition of venous pathology and anatomic location of target veins.

$$
\text { clinical study }
$$

PREMiSe study (USA)

Multicenter Canadian study (Canada)

Brave Dreams study (Italy)

University of Pisa study (Italy)

\section{venographic definition of pathology}

$\geq 50 \%$ luminal diameter reduction

$>50 \%$ luminal diameter reduction

according to the ISNVD Consensus Document

according to the ISNVD Consensus Document +

pressure gradient measurement in selected cases not mentioned by the authors of the Canadian study. It is therefore possible that the criterion of $>50 \%$ luminal diameter reduction in CCSVI patients is not adequate. Moreover, it is possible that in these studies the actual lesions responsible for impaired cerebral venous drainage (typically, it is an abnormal jugular valve) were not addressed [24, 25].

\section{Discussion}

Taking into account all these data and considering strong and weak points of aforementioned clinical trials, it can be concluded that venous angioplasty should not be used as a routine treatment modality in MS patients [18]. However, in contrast to the opinions of some authors [26, 27], a possibility that some MS patients may benefit from endovascular treatment cannot be ruled out. This particular subgroup may comprise patients at early stage of the disease and presenting with lesions that can easily be managed with balloon angioplasty, such as septum localized in the proximal part of internal jugular vein.

Recently, an expanded analysis of the Brave Dreams study has been revealed. This analysis, which involved also secondary progressive MS patients who participated in this study, utilized the venographic classification of CCSVI lesions suggested by Giaquinta [20] and focused at MRI findings after 12-month follow-up, demonstrated significantly less new MS plaques revealed by MRI in the treatment arm of the study. Moreover, patients with favorable morphology of CCSVI lesions, such as focal or segmental defects were significantly more likely to be free from new MS lesions in comparison with patients presenting with less favorable morphology of venous abnormalities, such as long intraluminal defects, hypoplasia of the internal jugular vein or external compression of this vein by adjacent muscles [28, 29].

Taking into account this new analysis, it seems that we need more studies evaluating clinical efficacy of venous angioplasty in selected MS patients. Importantly, all aforementioned trials and also the open-label surveys have demonstrated that venous angioplasty in MS patients is a safe procedure and that serious adverse events associated with this treatment are rare $[6,10,11$, $14,16,17,20,25,30,31]$. Therefore, from ethical point of view, new trials performed in selected patients, considering low risk and possible clinical benefit, seem justifiable.

\section{Conflict of Interest}

The authors declare that they have no conflict of interest.

\section{References}

[1] Zamboni P. The big idea: iron-dependent inflammation in venous disease and proposed parallels in multiple sclerosis. J Roy Soc Med 2006; 99: 589593

[2] Zamboni P, Menegatti E, Bartolomei I et al. Intracranial venous haemodynamics in MS. Curr Neurovasc Res 2007; 4: 252-258

[3] Zamboni P, Menegatti E, Galeotti R et al. The value of cerebral Doppler venous haemodynamics in the assessment of multiple sclerosis. J Neurol Sci 2009; 2 (82): 21-27

[4] Zamboni P, Galeotti R, Menegatti E et al. Chronic cerebrospinal venous insufficiency in patients with multiple sclerosis. J Neurol Neurosurg Psychiatry 2009; 80: 392-399

[5] Zamboni P, Galeotti R. The chronic cerebrospinal venous insufficiency syndrome. Phlebology 2010; 25: 269-279 
[6] Zamboni P, Galeotti R, Menegatti E et al. A prospective open-label study of endovascular treatment of chronic cerebrospinal venous insufficiency. J Vasc Surg 2009; 50: 1348-5138

[7] Ludyga T, Kazibudzki M, Latacz P et al. Early results of a prospective open-label study on endovascular treatments for chronic cerebrospinal venous insufficiency in the patients with associated multiple sclerosis. Phlebol Rev 2011; 19: 9-14

[8] Lugli M, Morelli M, Guerzoni S et al. The hypothesis of patho-physiological correlation between chronic cerebrospinal venous insufficiency and multiple sclerosis: rationale of treatment. Phlebology 2012; 27 (Suppl. 1): 178-186

[9] Petrov I, Grozdinski L, Kaninski G et al. Safety profile of endovascular treatment for chronic cerebrospinal venous insufficiency in patients with multiple sclerosis. J Endovasc Ther 2011; 18: 314-323

[10] Simka M, Janas P, Ludyga T et al. Endovascular treatment for chronic cerebrospinal venous insufficiency in patients with multiple sclerosis. Vasc Dis Manag 2012; 9: 149-154

[11] Denislic M, Milosevic Z, Zorc M et al. Disability caused by multiple sclerosis is associated with the number of extracranial venous stenoses: possible improvement by venous angioplasty. Results of a prospective study. Phlebology 2013; 28: 353-360

[12] Beggs CB, Giaquinta A, Veroux M et al. Mid-term sustained relief from headaches after balloon angioplasty of the internal jugular veins in patients with multiple sclerosis. PLoS ONE 2018; 13: e0191534

[13] Bavera PM. Multiple sclerosis: is the Brave Dreams Study a tombstone for CCSVI and eventual surgical procedures? An open discussion. Acta Phlebol 2018; 19: 47-48

[14] Siddiqui AH, Zivadinov R, Benedict RH et al. Prospective randomized tria of venous angioplasty in MS (PREMiSe). Neurology 2014; 83: 441-449

[15] Traboulsee AL, Machan L, Girard M et al. Safety and efficacy of venoplasty in MS. Neurology 2018; 91: e1660-e1668

[16] Zamboni P, Tesio L, Galimberti S et al. Efficacy and safety of extracranial vein angioplasty in multiple sclerosis. JAMA Neurol 2018; 75: 35-43

[17] Napoli V, Berchiolli R, Carboncini MC et al. Percutaneous venous angioplasty in patients with multiple sclerosis and chronic cerebrospinal venous insufficiency: a randomized wait list control study. Ann Vasc Surg 2020; 62: 275-286

[18] Zamboni P, Zivadinov R. Extracranial veins in multiple sclerosis: is there a role for vascular surgery? Eur J Vasc Endovasc Surg 2018; 56: 618-621

[19] Calligaro KD, Amankwah KS, D'Ayala M et al. Guidelines for hospital privileges in vascular surgery and endovascular interventions: Recommendations of the Society for Vascular Surgery. J Vasc Surg 2018; 67: 13371344
[20] Giaquinta A, Beggs CB, Veroux $M$ et al. Factors influencing the hemodynamic response to balloon angioplasty in the treatment of outflow anomalies of internal jugular vein. J Vasc Surg Venous Lym Dis 2017; 5 : 777-788

[21] Traboulsee AL, Knox KB, Machan L et al. Prevalence of extracranial venous narrowing on catheter venography in people with multiple sclerosis, their siblings, and unrelated healthy controls: a blinded, case-control study. Lancet 2014; 383: 138-145

[22] Simka M, Hubbard D, Siddiqui AH et al. Catheter venography for the assessment of internal jugular veins and azygous vein: Position statement by expert panel of the International Society for Neurovascular Disease. Vasa 2013; 42: 168-176

[23] Zivadinov R, Bastianello S, Dake MD et al. Recommendations for multimodal noninvasive and invasive screening for detection of extracranial venous abnormalities indicative of chronic cerebrospinal venous insufficiency: a position statement of the International Society for Neurovascular Disease. J Vasc Interv Radiol 2014; 25: 1785-1794. e17

[24] Simka M, Latacz P. Abnormal valves of the internal jugular veins: morphology, diagnostics and clinical relevance. In: Bennington EH, editor Horizons in World Cardiovascular Research. Volume 16 New York: Nova Science Publishers; 2019: 1-22

[25] Simka M. Chronic cerebrospinal venous insufficiency: current perspectives. J Vasc Diagn 2014; 2: 1-13

[26] Green AJ, Hooman K, Josephson SA. Combating the spread of ineffective medical procedures: a lesson learned from multiple sclerosis. JAMA Neurol 2018; 75: 15-17

[27] Jagannath VA, Pucci E, Asokan GV et al. Percutaneous transluminal angioplasty for treatment of chronic cerebrospinal venous insufficiency (CCSVI) in people with multiple sclerosis. Cochrane Database Syst Rev 2019; 5: CD009903

[28] Zamboni P, Galeotti R, Salvi F et al. Effects of venous angioplasty on cerebral lesions in multiple sclerosis: expanded analysis of the Brave Dreams double-blind, sham controlled randomized trial. J Endovasc Ther 2019. doi: $10.1177 / 1526602819890110$

[29] Simka M, Majewski E, Fortuna M et al. Internal jugular vein entrapment in a multiple sclerosis patient. Case Rep Surg 2012; 2012: 293568

[30] Mandato KD, Hegener PF, Siskin GP et al. Safety of endovascular treatment of chronic cerebrospinal venous insufficiency: a report of 240 patients with multiple sclerosis. J Vasc Intervent Radiol 2012; 23: 55-59

[31] Ludyga T, Kazibudzki M, Simka M et al. Endovascular treatment for chronic cerebrospinal venous insufficiency: is the procedure safe? Phlebology 2010; 25: 286-295 